\title{
WEIGHT CHANGES DURING PROLONGED EXERCISE
}

\author{
A. W. S. WATSON, B.Sc., M.Sc., F.R.A.M.I. \\ Dept. of Physiology, University of Aberdeen
}

\section{Introduction}

Outward bound Moray runs a series of $\mathbf{2 6}$ day courses of out door activity, which are attended by youths and young adults from a wide range of backgrounds. Many of the participants are seconded from industrial apprenticeships, others are from the services, police cadetships, or are sponsored from school by local education authorities. A number of the participants are financed privately and a small proportion are from abroad. The students live at the school for the duration of the course and take part in a wide range of out door activities including climbing and hill walking, camping, sailing, seamanship, swimming and life saving. The aim of the course is not primarily to improve the physical condition of the students. However they are kept extremely active throughout the 26 days that they spend at the school and some change in this direction would be expected. The height and weight of each student is measured as a matter of routine at the beginning and end of each course, and although no formal analysis of these data has ever been made the general impression was gained that the students increased in weight during their stay at the school. Since this is contrary to the usual effect of prolonged exercise on human body weight, a systematic study of the students on one such course was undertaken. The body weight of each student was measured under standardised conditions at the beginning and end of the course. In order to establish if any observed weight change might be due to variation in adipose tissue, subcutaneous fat was estimated by taking skinfold measurements. No method of estimating possible changes in mass of skeletal muscle tissue was available, but an estimate of changes in muscular strength was made in a small group of the students.

\section{Methods}

Measurements of body weight and skinfold thickness on three sites were made (see below) at the beginning and end of the course on all the students at the school. lgnoring students who either arrived late or left early and were seen only once, measurements were made on 91 subjects. The students started to arrive on the afternoon of the first day of the course and measurements were started on the first batch of students on arrival. The others were measured between 9.00 am and noon on the second day. At the end of the course the same measurements were taken in the afternoon of the 25th day and the morning of the 26th. An attempt was made to take the two sets of measurements on a particular student at the same time of day on each occasion. This was generally successful but was not possible in all cases. The student's weight was measured, without clothing, to the nearest 0.5 kilo on scales which had previously been calibrated. Skinfold measurements were made with Harpenden Skinfold calipers on three sites:- Over the left biceps, on the left shoulder subscapular, and on the mid-line of the abdomen. The measurements of strength which were made on some of the subjects were taken with a Collins elliptical hand-grip dynamometer and a TKK push-pull dynamometer. No measurement of height was taken, the assumption being made that no measurable change occured in this group of average age 17.6 years, during the 26 days of the course.

\section{Results}

The majority of subjects gained in weight during the 26 days of the course.

\section{TABLE /}

Change in weight

Number of subjects

GAIN

LOSS

NO CHANGE

TOTAL

The mean weight of the subjects at the start of the course was $64.23 \pm 7.44 k$ (mean \pm S.D.) and the mean weight gain during the 26 days of the course was $0.912 \pm$ $0.224 k$ (mean \pm S.E.M.)

A paired $t$ test shows this change to be statistically highly significant. $(p<0.01)$

The majority of subjects showed a decrease in skinfold measurements during the period of the course.

\section{TABLE //}

Change in skinfolds

Number of subjects

GAIN

LOSS

NO CHANGE

TOTAL 
The mean change in skinfold measurements was a decrease of $2.5 \pm 0.324 \mathrm{~mm}$. (mean \pm S.E.M.) A paired $\mathrm{t}$ test shows this change to be statistically highly significant. $(p<0.01)$

Thus the majority of students increased in weight while at the same time decreasing in skinfold measurements. A minority of the students (19/91) lost weight during the course. It might have been the case that this group lost weight because they were over-weight when the course began and so lost more weight than the other students. If this were so larger changes in skinfold measurements would be expected for this group than for the students as a whole. The mean decrease in skinfold measurements for the group who lost weight was $4.3 \pm 0.91 \mathrm{~mm}$. While this is larger than for the students as a whole the difference is small and fails to reach statistical significance. The overall correlations between initial weight and weight gain, and between initial skinfold measurement and skinfold loss, were also small being -0.25 and +0.22 respectively. Thus there was only a slight tendency for the lightest to gain the most weight and for the fattest to lose the most in skinfold measurements.

\section{Discussion}

The group of students as a whole showed a statistically highly significant gain in body weight while at the same time significantly decreasing in skinfold measurements. It would appear that a small decrease in adipose tissue occurred concurrent with a rather larger increase in the mass of total body tissue. The most probable site of this increase would appear to be skeletal muscle. The attempt to demonstrate an increase in muscular strength was unsuccessful as the changes in performance on the dynamometer tests were vary small and failed to reach statistical significance. The group of students who undertook these tests showed a slight decrease in hand grip and little change with the push-pull dynamometer. Although these results would not appear to support the hypothesis of an increase in muscular strength, other explanations are also possible. It is possible that the tests of strength were insufficiently sensitive or reliable to detect changes which did in fact occur.

This seems unlikely as a high test-retest reliability coefficient has been reported for these measurements, (Campbell and Tucker 1967), and they have been successfully used to demonstrate short term changes in strength in similar groups (Watson 1972). The more likely explanation would seem to be that the dynamometer tests were specific to the arms and upper trunk and did not measure leg or upper trunk strength, the areas where any increase would be most likely to occur with such a programme of activities as was undertaken by the students on this course.

The activities undertaken on the course consisted of long periods of moderate or moderately heavy exercise, rather than short intensive periods of near maximal exertion. The activities were not primarily designed for the increase of strength which tends to occur when the muscle groups are exercised fairly heavily. (Hettinger and Müller 1953; Hettinger 1955). The type of activity actually undertaken would be expected to be performed at relatively low R.Q. when fatty acid catabolism is high, (Åstrand 1967). These are ideal conditions for loss of body fat and it is perhaps suprising that an overall loss in body weight did not occur during the period of the course. The reason may well be that the subjects had little body fat to lose. The mean skinfold measurements of the group at the start of the course was well below the national average for subjects of this age.

\section{Acknowledgement}

The author would like to thank the warden of Outward Bound Moray, W. R. Swanson Esq., and his staff, for their help in carrying out this investigation.

\section{REFERENCES}

1. ÅSTRAND, P. O. (1967) FED. Proc. vol. 26, no. 6

2. CAMPBELL, W. R. and N. M. TUCKER (1967) An Introduction to Tests and Measurements in Physical Education. Bell and Son, London.

3. HETTINGER, T. (1955) Internationale Zeitschrifft fur angewandte Physiologie einschliesslich Arbeitsphysiologie 16: 95-98.

4. HETTINGER, T. and MÜLLER, E. A. (1953) Internationale Zeitschrift fur angewandte Phsiologie einschliesslich Arbeitsphysiologie 5; 1, 11-126.

5. WATSON, A. W. S. (1972) British Journal of Physical Education, 3, 3, XX. 